\title{
Nest site habitat selection and nesting performance of the Great Bustard Otis tarda in southern Portugal: implications for conservation
}

\author{
PEDRO ROCHA, MANUEL B. MORALES and FRANCISCO MOREIRA
}

\section{Summary}

We present results on breeding parameters, nesting performance and nest habitat selection of the globally threatened Great Bustard Otis tarda, gathered during a 3-year study in Castro Verde (southern Portugal). A total of 107 nests were located. The estimated average onset of laying was 22 April (SD $=12$ days, $n=8)$. The incubation period ranged from 25 March to 15 June. Nearly $95 \%$ of females incubated between 1 April and 31 May. Mean clutch size was 2.12 (SD $=0.69$, $n=86$ ), showing no significant inter-annual differences. There was no significant relationship between clutch size and average nest finding date, although, on average, nests were found later each year. Hatching occurred between 21 April and 26 June. The estimated proportion of eggs hatched per nest (hatching percentage) was $87.5 \%$ in $2002(n=8), 64.0 \%$ in $2003(n=33)$ and $75.8 \%$ in $2004(n=33)$. Overall nesting success for the three years was $71 \%(n=107)$. The main causes of nesting failure were agricultural activities, mainly ploughing and harvesting, followed by corvid predation. Nests were spatially aggregated up to $800-1,500 \mathrm{~m}$. At larger scales, the spatial distribution of nests can be considered random or uniform. Females showed a clear preference for nesting in cereal fields, followed by young fallows, old fallows, ploughed fields and then other habitats, although the intensity of selection of particular habitats varied between years. Nests were associated with both cereals and fallows, thus aggregating where those habitat types occurred within the study area. These results provide the first complete description of the nesting process in a Great Bustard population, as well as important cues to the assessment of conservation measures implemented in Castro Verde, an area holding around $80 \%$ of the Portuguese population of this species (application of EU agri-environmental schemes, power line signalling, water-point provision in dry years).

\section{Introduction}

An adequate knowledge of species' breeding success and causes of reproductive failure is critical in assessing the health of their populations and determining their conservation status (e.g. Sutherland 2000). In precocial birds, estimating breeding success is difficult because chicks leave the nest soon after hatching. In some cases, chick survival can be calculated using capture and release techniques and statistical models (McGowan et al. 2009). However, this is not always feasible and parameters of nesting performance (i.e. number of nests, clutch size, hatching success) are often used. Additionally, most of these species are ground nesters and are therefore particularly sensitive to changes in land use intensity (i.e. cultivation and grazing intensity in farmland habitats; Báldi et al. 2005, Guerrero et al. 2011). Consequently, knowledge of their nesting habitat preferences is a prerequisite to assess and minimise the impact of such changes on bird breeding performance.

The Great Bustard Otis tarda is a ground-nesting, precocial bird inhabiting natural steppes and cereal-cultivated areas of the Palearctic Region (Del Hoyo et al. 1996). The species is globally 
threatened, listed as "Vulnerable" (BirdLife International 200o), and classified as SPEC I in Europe (Tucker and Heath 1994). During the 2oth century, the Great Bustard suffered a steep decline throughout its range and went extinct in many countries, mainly due to agricultural habitat loss and degradation (Cramp and Simmons 1980, Morales and Martín 2002, Lopes-Jamar et al. 2011). The population stronghold is in the Iberian Peninsula, with nearly 30,000 birds in Spain (Palacín and Alonso 2008) and 1,400 in Portugal (Pinto et al. 2005).

Population viability analyses have identified female breeding performance as a key parameter in the persistence of Great Bustard populations (Streich et al. 1996, Lane and Alonso 2001, Alonso et al. 2004). This result is consistent with the breeding biology of the Great Bustard in which incubation and chick rearing are exclusively undertaken by females (Cramp and Simmons 1980), as described in other lekking birds.

However, information on breeding parameters and female reproductive performance is lacking for many Great Bustard populations. Data on clutch size have been reported from north-west Spain (Ena et al. 1987), Hungary (Faragó 1992), south Portugal (Morgado and Moreira 2000) and the Saratov region of Russia (Shlyakhtin et al. 2004), while long term patterns in female reproductive success at the population and individual levels have been provided for north-west Spain (Morales et al. 2002). However, information on hatching success and causes of nesting failure is much scarcer (but see Ena et al. 1987 and Magaña 2007).

Finally, reports on nest site habitat use or selection are also rare, although results from a few studies have been published on this issue during the last decade (Morgado and Moreira 2000, Shlyakhtin et al. 2004, Magaña et al. 2010).

In this paper, we present results on Great Bustard breeding parameters, nesting performance and nesting habitat selection in the Castro Verde Special Protection Area (SPA), in southern Portugal. This area holds around $80 \%$ of the Portuguese population of the species, which is almost entirely concentrated in the Alentejo region (Pinto et al. 2005). Although some data on Great Bustard clutch size and nesting habitat use have already been provided for this area (Morgado and Moreira 2000), results presented here correspond to a much larger and systematically gathered sample obtained over three years, and thus they can be considered the most representative results on nesting performance and habitat selection for the main Great Bustard population of Portugal. Moreover, they provide the first complete description of the nesting process, from nesting habitat selection to nesting success, in a population of this species. These results will provide cues to the assessment of practical management measures for steppe bird conservation currently being applied at the Castro Verde SPA, with a focus on the specific agri-environmental scheme ongoing in the area since 1995 .

\section{Methods}

\section{Study area}

The study was carried out in the cereal steppe of Castro Verde $\left(37^{\circ} 43^{\prime} \mathrm{N}, 7^{\circ} 57^{\prime} \mathrm{W} ; 90.5\right.$ ha; Figure 1), an SPA considered the most important area for steppe birds in Portugal (Grimmet and Jones 1989), holding around 1,100 Great Bustards (Pinto and Rocha 2006). This area is located in the Meso-Mediterranean bioclimatic stage (Rivas-Martínez 1981). Altitude ranges from 150 to $240 \mathrm{~m}$ asl, annual average temperatures range from 11.0 to $16.0^{\circ} \mathrm{C}$, and annual rainfall from 350 to $650 \mathrm{~mm}$. The landscape is an open farmland mosaic resulting from rotational dry cereal cultivation, dominated by cereal crops (mainly wheat Triticum aestivum and oats Avena sativa), fallow land, pastures, and ploughed fields. The traditional agricultural system used in this region is as follows: each farm is divided into parcels, each of which lies under cereal cultivation for two years $\left(1^{\text {st }}\right.$ year wheat, $2^{\text {nd }}$ year oats), after which the land is left fallow for $2-3$ or more years. The parcel is then ploughed to re-initiate the rotation cycle. Fallow land is generally used as pasture for sheep and cattle. Tree cover is restricted to some plantations of olive trees Olea europaea and peripheral cleared oak Quercus rotundifolia and Q. suber woodland (or montados). 

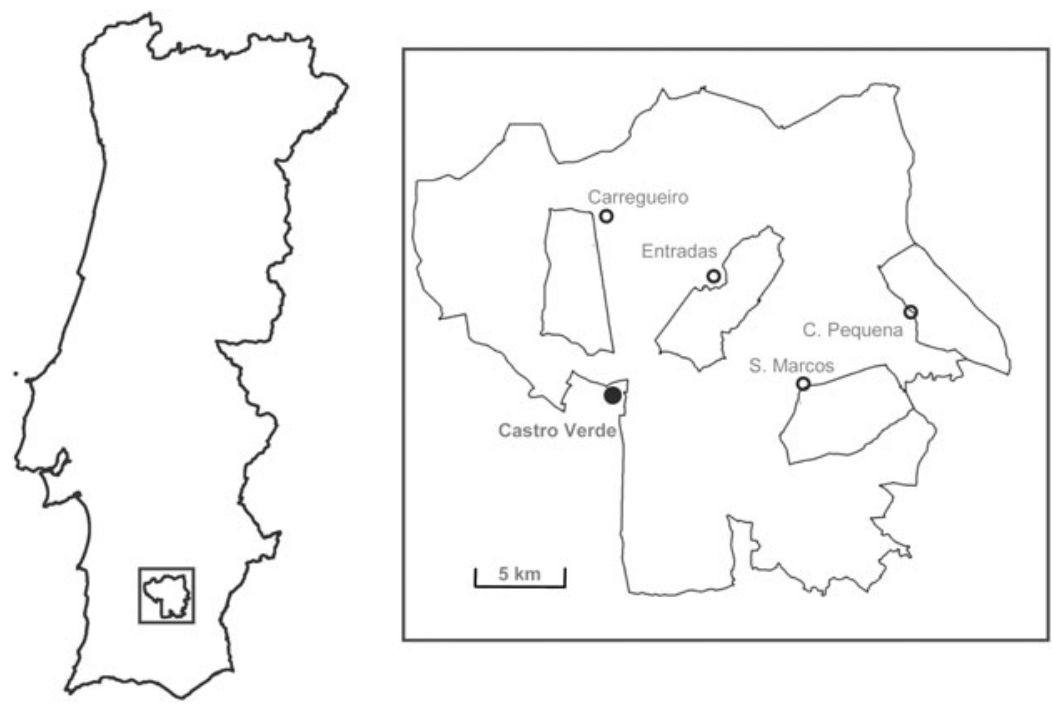

Figure 1. Map of the study area showing its location in Southern Portugal and the limits of the four study sub-areas.

Increasing areas of scrub (mainly Cistus ladanifer) occur on rocky outcrops and abandoned cropland.

\section{Nest data collection}

Data were collected during the nesting seasons (March-June) of 2002, 2003, and 2004 throughout the entire study area (Figure 1). Nests were detected by means of (i) field surveys (either following females that exhibited nesting behaviour, or systematic search transects), and (ii) directed searches based on information about nest locations from inquiries to farmers, shepherds and ornithologists. Search effort was homogeneous across the study area and between different habitat types (see below). Although nests may be harder to find in cereal fields, and a larger number of nests may have been overlooked in that habitat type during surveys, they are easily detected by farmers while harvesting. Therefore the potential bias in nest detection between habitats can be considered small. In all cases, searches were performed so as to minimise disturbance of incubating females and human influence on breeding success. After they were located, nests were visited only once and always after hatching. In order to guarantee this, nests were visited 28 days after finding, which corresponds to the maximum length of the incubation period in the species (Cramp and Simmons 1980). On each visit, vegetation around the nest was rearranged, and visit length was kept under one minute.

The nesting habitat assigned to each nest corresponded to the habitat existing on the estimated laying date (it might have changed when the visit was carried out, e.g. cereal fields that were harvested). For each nest, the following data were recorded or estimated, based on egg shell remains present in the nest and following recommendations by Sutherland et al. (2004):

- Nest finding date. Date on which any given nest with incubating female was found.

- Incubation period. An estimate of the incubation period was obtained for nests of known hatching date, taking the preceding 25 days as the incubation period.

- Clutch size. Number of eggs per complete clutch. Predated or abandoned clutches were not considered (predation frequently prevents the correct assessment of clutch size from shell remains, and abandonment may occur before clutch completion). 
Table 1 . Description of habitat types present in the study area.

\begin{tabular}{lc}
\hline Habitat type & Description \\
\hline Young fallows & One-year old fallows, corresponding to stubble fields \\
& from the previous harvest season \\
Old fallows & Two-year old and older fallows and pastures \\
Cereal & Fields cultivated with wheat Triticum aestivum or oats \\
& Avena sativa \\
Ploughed fields & Fields with no or very little vegetation cover due to \\
& ploughing \\
Olive groves & Parcels with traditional olive tree cultivation \\
Legumes & Fields cultivated with legumes, mainly chickpea Cicer \\
& arietinum or pea Pisum sativum \\
Afforestation & Parcels planted with young trees (pines Pinus pinea \\
and evergreen oaks Quercus rotundifolia, Q. suber) & Habitats covering less than $1 \%$ of the total area \\
Others & (Eucalyptus sp. plantations, scrubland, riverine \\
& vegetation, irrigated crops, etc.) \\
\hline
\end{tabular}

- Hatching date. Determined by direct observation of females with hatchlings (chicks leave the nest a few hours after hatching; Cramp and Simmons 1980).

- Hatching percentage. Defined as the proportion of eggs per clutch that produced a chick. Only clutches in which the total number of eggs laid could be obtained from the egg shell remains were considered (hatched eggs are easily identified from shell remains; in some cases this was confirmed by direct observation of the family). Again, clutches predated (evaluated from shell remains) or abandoned due to human disturbance (when no sign of incubation was detected after human contact) were excluded.

- Nesting success. A nesting attempt was considered successful whenever one or more eggs hatched in the corresponding nest.

\section{Nesting habitat availability}

The nest site habitat selection analysis was restricted to four sub-areas within the SPA for which habitat information was available in the three years of study (Figure 1). Aerial photographs and their corresponding field checks were used to assess the agricultural substrate of every parcel in these sub-areas, along with all non-agricultural land covers. This information was incorporated in a Geographical Information System (GIS). The area covered by the different agricultural habitats was calculated using the xtools extension of Arcview 3.2 (ESRI 1999). The habitat categories considered are described in Table 1 .

Habitat availability changed during the study period, due to agricultural activities such as ploughing or cereal harvesting. Thus, habitat availability was mapped at the beginning of the study (February/March) and updated at least three times during the breeding period, by travelling through the areas and registering changes in the different field parcels.

Table 2. Number and percentage of Great Bustard nests found in different habitat types of the study area in each of the study years.

\begin{tabular}{llllll}
\hline Year & $n$ & Fallow & Cereal & Ploughed & Afforestation \\
\hline 2002 & 16 & $10(62.5 \%)$ & $3(18.6 \%)$ & $2(12.5 \%)$ & $1(6.3 \%)$ \\
2003 & 48 & $28(58.3 \%)$ & $17(35.4 \%)$ & $2(4.2 \%)$ & $1(2.1 \%)$ \\
2004 & 37 & $14(37.8 \%)$ & $22(59.5 \%)$ & 0 & $1(2.7 \%)$ \\
Total & 101 & $52(51.5 \%)$ & $42(28.7 \%)$ & $4(3.9 \%)$ & $3(2.9 \%)$ \\
\hline
\end{tabular}




\section{Data analyses}

Potential between-year differences in clutch size were tested by means of non-parametric Kruskal-Wallis ANOVA (Zar 1996). The relationship between clutch size and the date of nest finding was explored by means of a General Linear Model (GLM), in which nest finding date was the response variable, and clutch size and year were used as categorical factors. The interaction between those factors was also tested. The normal distribution of the response variable residuals was verified by means of the Kolmogorov-Smirnov test (Zar 1996). The spatial distribution pattern of nests in the study area was examined by means of Ripley's K function (Wiegand and Moloney 2004). This function allows second order spatial analysis, taking into account the variance in the distance between points where nests were found. Unlike other methods, this function also allows the detection of changes in nest location patterns as a function of spatial scale. Ripley's L function is a transformation of the $\mathrm{K}$ function that is more often used since it eliminates the effect of scale in the case of independent patterns and stabilises the variance (Ripley 1981), which assists the interpretation of the results. In order to establish whether the L function obtained differed significantly from a random null model, $95 \%$ confidence intervals were calculated by means of Monte Carlo permutations of the null model. The spatial pattern is considered random if the obtained function is delimited by the confidence intervals, uniform if it is above these intervals, and aggregated if it is below the confidence band. In order to maximise sample sizes, this analysis was performed only for years 2003 and 2004 using the Passage software (Rosenberg 2009).

Between-year differences in nesting habitat use were examined by means of the non-parametric G-test (Zar 1996). Selection ratios (Manly et al. 1993, Arthur et al. 1996) were used to assess habitat selection patterns by nesting females. These habitat selection analyses were limited to the 53 nests located in the four sub-areas for which habitat cartography was available. Because habitat availability changed between nesting areas, years and within season (due to agricultural works), we calculated the ratios using a modification of Arthur et al.'s (1996) method (see Moreira et al. 2004). The sampling unit was the nest location. For each nest, we calculated a set of selection ratios as $1 /(\%$ availability) for the habitat type that was used for nesting and for the remaining available types. Observations of located nests were then used to derive maximum likelihood estimates of selection ratios (conceptually equivalent to the mean ratio of use to availability) by an iteration procedure (for further details, see Moreira et al. 2004). Estimating selection ratios required that the selection ratio for one habitat be set equal to 1.0, and selection for other habitat types estimated in relation to this reference habitat. The magnitudes of the selection ratios indicate the intensity of selection for each type, relative to the reference type. Old fallows were used as the reference habitat, because they were common and used in all areas over the three years of study. Thus, selection ratios $>_{1}$ indicate habitats with greater use (relative to availability) than old fallow fields, whereas ratios $<_{1}$ indicate habitats with less use.

To determine if habitat use differed (relative to availability), a likelihood-ratio test (Manly et al. 1993, Arthur et al. 1996) was used to compare a null model that assumed equal use of all habitats and a model that allowed habitat use to differ. If the test suggested that the selection model provided a better fit to the data, then we concluded that habitat use was selective (i.e. non-random). A similar approach was used to determine if patterns of selection differed between years (only 2003 and 2004, as for 2002 sample size was too small). The likelihood-ratio was used to determine if a better fit was obtained by modelling each year separately, versus a model that pooled all data (Arthur et al. 1996). To determine which habitat types were selected differently, we calculated the variance/covariance matrix for each set of selection ratios and tested the significance of differences between pairs of selection ratios using a z-test. Selection ratios for habitats that were not used (ratio $=0$ ) were assumed to differ from ratios for which the $95 \%$ confidence interval (CI) excluded o, but not from habitats for which the $95 \%$ CI included o (for further details, see Moreira et al. 2004). Finally, in order to assess the existence of spatial association between Great Bustard nests and preferred habitats identified by habitat selection analysis, the degree of spatial aggregation between nests and 
fields with those habitat types was tested by means of a bivariate Ripley's L function analysis (Wiegand and Moloney 2004) between nest site locations and the centroids of fields covered by selected habitat types present in the study area. This analysis is a variant of the univariate Ripley's L function in which the spatial relationship between two different types of events is based on the distribution of distances of type 1 events (in this case nest locations) with respect to type 2 events (centroids of fields with favourable habitat types). In order to maximise its robustness, this analysis was performed with data from 2003, which was the year with the largest sample size. Again, statistical significance of the patterns detected was tested using Passage (Rosenberg 2009). All other statistical analyses were performed using SPSS (SPSS 1999) and an EXCEL spreadsheet. Significance level of all tests was set at $P<0.05$.

\section{Results}

\section{Nesting performance}

A total of 107 nests were located in the whole study area over the three years of study ( 17 nests in 2002, 53 nests in 2003, and 37 nests in 2004). Only for eight nests was it possible to precisely determine the onset of laying, which occurred, on average, on 22 April ( $\pm \mathrm{SD}=12$ days). Incubating females were detected between I April and 12 June. Most incubating females (95.0\%) were detected between 6 April and 31 May.

Clutch size could be reliably assessed in 86 nests. The mean clutch size found was 2.12 ( $\mathrm{SD}=0.69$, $n=86$ ), with no between-year differences found (Kruskall-Wallis, $\chi_{2}^{2}=2.28, P>0.05$ ). The GLM analysis found no significant relationship between nest finding date and clutch size $\left(F_{2,61}=1.58\right.$, $P=$ o.22). However, the effect of both year and the interaction between year and clutch size were statistically significant $\left(\mathrm{F}_{2,61}=5.96, \mathrm{P}<0.005\right.$ and $\mathrm{F}_{4,61}=2.76, \mathrm{P}<0.05$, respectively). The average date of nest finding was later from year to year, that is, earliest in 2002 and latest in 2004 . Additionally, the average finding date of nests with one egg was delayed from year to year so that, in 2004, the average finding date of one egg clutches was significantly later than those of two- and threeegg clutches.

Hatching occurred between 18 April and 26 June. For the eight nests of known laying onset, the mean hatching date was 17 May. Global nesting success for the three years was $71 \%$, calculated for a sample of 74 located nests. Hatching percentage was $87.5 \%(n=8), 64.0 \%(n=33)$ and $75.8 \%(n=33)$ for 2002, 2003 and 2004, respectively. The main cause of nesting failure was agricultural activity ( 11 nests in the sample of 21 failed clutches). Among these activities, ploughing and harvesting caused six and two losses (plus one clutch destroyed by one farmer walking in a cereal field) respectively, while livestock trampling destroyed two clutches. Four nests were predated by corvids (confirmed by the presence of typical holes in shells) and six others were abandoned by females.

\section{Nesting habitat use and selection}

Great Bustard nesting territories in the study area occupied a minimum area of 44.1 ha, calculated from a minimum convex polygon (MCP, see Hooge and Eichenlaub 1997) built on a sample of 96 precisely located nests (not only the field where the female was nesting, but the exact nest location within the field were known). The highest nest density was observed in 2003 , with 53 nests located in 36,700 ha ( 1.4 nests/10o ha), locally reaching up to 8.0 nests/1oo ha across a 2,500 ha area). The minimum distance between neighbour nests was $60-70 \mathrm{~m}$. Nests were spatially aggregated in the two years considered, although the degree of aggregation varied as the scale increased. The aggregation pattern was statistically significant, indicating nest clustering up to c.1,500 $\mathrm{m}$ in 2003 and c. $800 \mathrm{~m}$ in 2004, being maximal at c.700 $\mathrm{m}$ in both years (Figure 2). At larger scales, the spatial distribution of nests can be considered random up to $\mathrm{c} .5,500 \mathrm{~m}$ in both years, and uniform thereafter. 

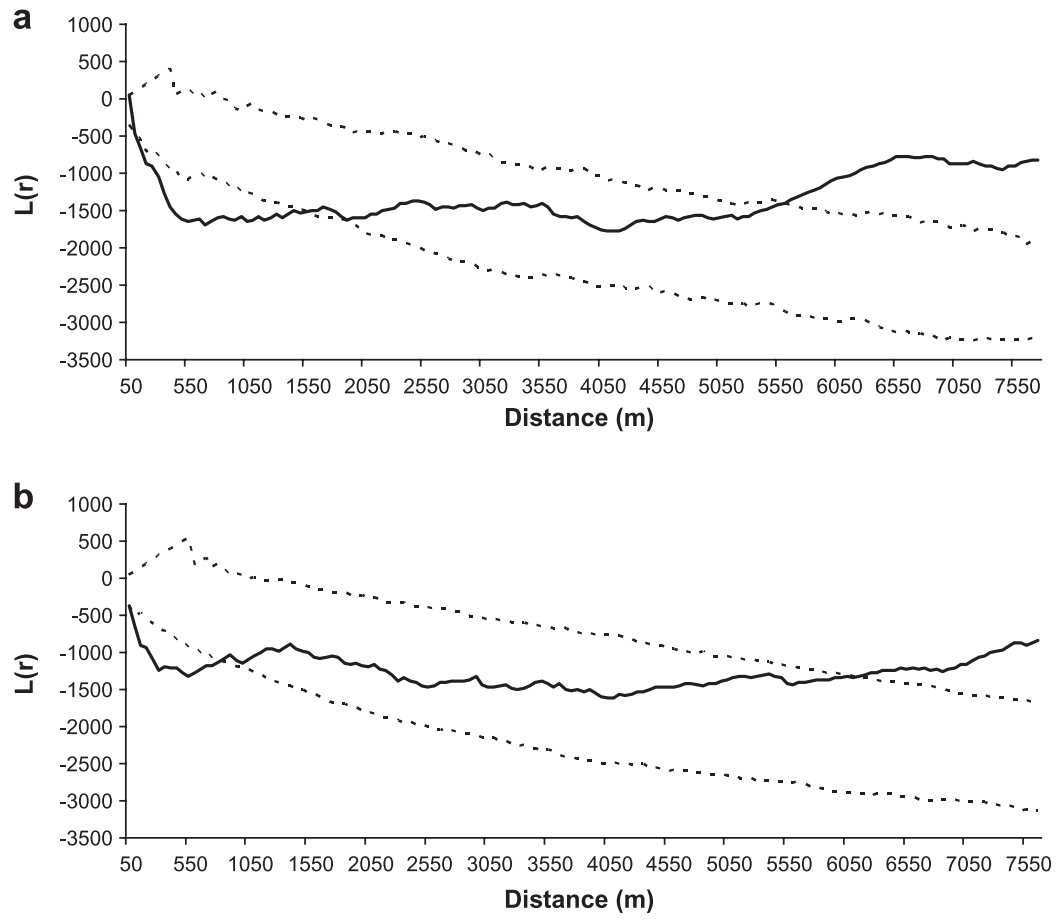

Figure 2. Results of the analyses of Ripley's function L(r) (solid line) of the spatial distribution of Great Bustard nests in Castro Verde in 2003 (a) and 2004 (b). The dashed lines represent $95 \%$ confidence limits resulting from the randomization of the distribution pattern (999 simulations). $\mathrm{L}(\mathrm{r})$ values within the $95 \%$ confidence limits indicate a random distribution, values below the interval indicate spatial aggregation and values above the interval indicate uniform distribution.

Nesting habitat was clearly determined for 101 nests. Nesting Great Bustards prefer fallows and cereal fields, and occasionally use ploughed fields and recent afforestation (Table 2). However, habitat type preferences changed from 2002 to 2004 (Table 2), particularly the use of fallows $(G=37.4, P<0.01)$ and cereal fields $(G=10.1, P<0.05)$. Over the three years of study, 53 nests were located in the four sub-areas for which a habitat map was available. The choice of nesting habitat by females was not random (Likelihood test, $P<0.05$ ). Preferred habitats were cereal fields, followed by young fallows, and old fallows, all three being significantly more selected than ploughed fields and others (pairwise z-tests, $P<0.05$ ) (Figure 3). Differences between years in the selection of habitats used common to both areas were significant (Figure $3 \mathrm{~b}$; likelihood test, $P<0.05)$. Cereal fields were more selected in 2004 compared to 2003.

Great Bustard nests were spatially associated to both cereals and fallows (both young and old ones) at intermediate scales. This spatial association disappears beyond a distance of $3,800 \mathrm{~m}$ for cereals and 4,80o for fallows (Figure 4).

\section{Discussion}

Our results from the Great Bustard population of Castro Verde help to complete the picture of the nesting process in this species, providing new information on phenology, reproductive parameters, nesting success, spatial distribution and nest-site habitat selection. 

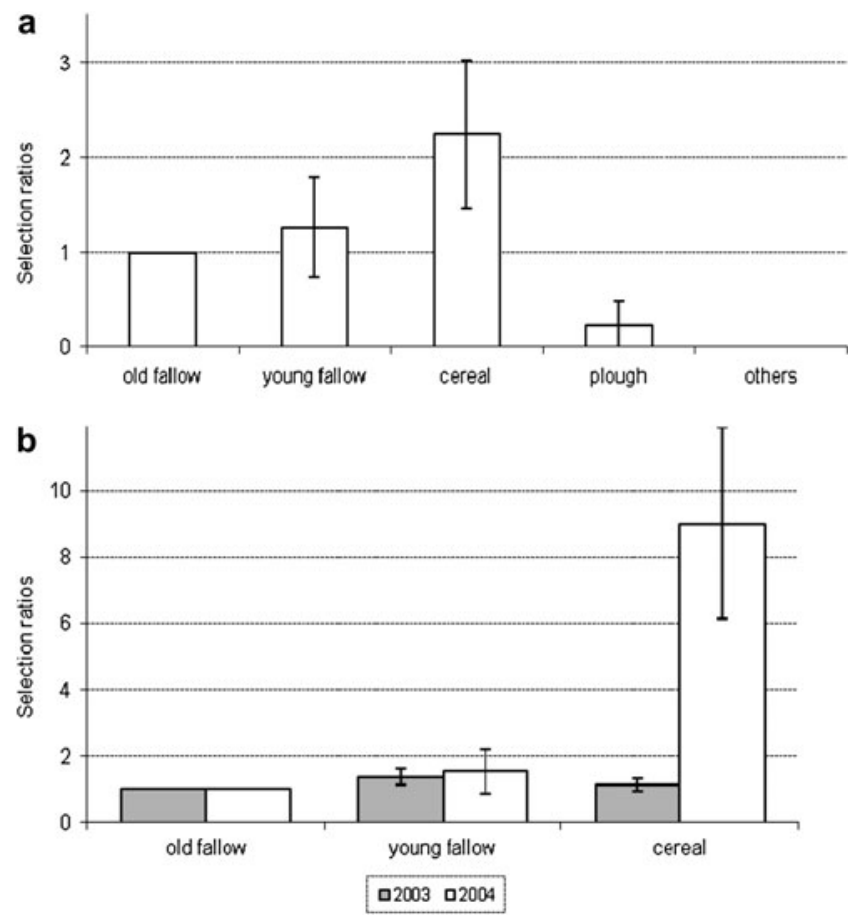

Figure 3. Nesting habitat selection by Great Bustard females in Castro Verde. (a) Overall selection pattern. (b) Between year differences for young fallow and cereal.

\section{Nesting phenology}

The nesting phenology described in this study basically coincides with the general pattern of the species in other areas of Iberia (Morales and Martín 2002). Nevertheless, the observation of incubating females as early as I April suggests that the onset of incubation in the study area may occur at least in late March. At the opposite extreme, the presence of incubating females as late as 12 June suggests that the last nests may be left in the second half of June. In any case, this breeding phenology seems to be around one month earlier than that reported by Shlyakhtin et al. (2004) for the Russian populations in the Saratov administrative region, where the earliest onset of laying described is around 25 April, although those authors provide no details on how that date was estimated, and thus comparisons should be made with caution. Nevertheless, these differences are expected for two populations in opposite extremes of the species distribution range in the Western Palearctic: ours under mild Mediterranean climate conditions, and the Russian one, in a harsh-winter and extremely continental region.

\section{Clutch size}

The average clutch size of $2.12(\mathrm{SD}=0.69)$ estimated in the current study is not substantially different from that found in other populations across the species distribution range. Faragó (1992) found an average clutch size of $1.93(\mathrm{SD}=0.58)$ in a sample of 850 clutches located in different Hungarian populations over 16 years, whereas Flint and Mishchenko (1991) and Shlyakhtin et al. (2004) estimated average clutch sizes of $1.93(n=155)$ and $2.10(\mathrm{SD}=0.06)$, respectively, in nests detected over several years in the Saratov region, Russia. Nevertheless, some studies have reported clearly larger average clutch sizes. Ena et al. (1987) found an 

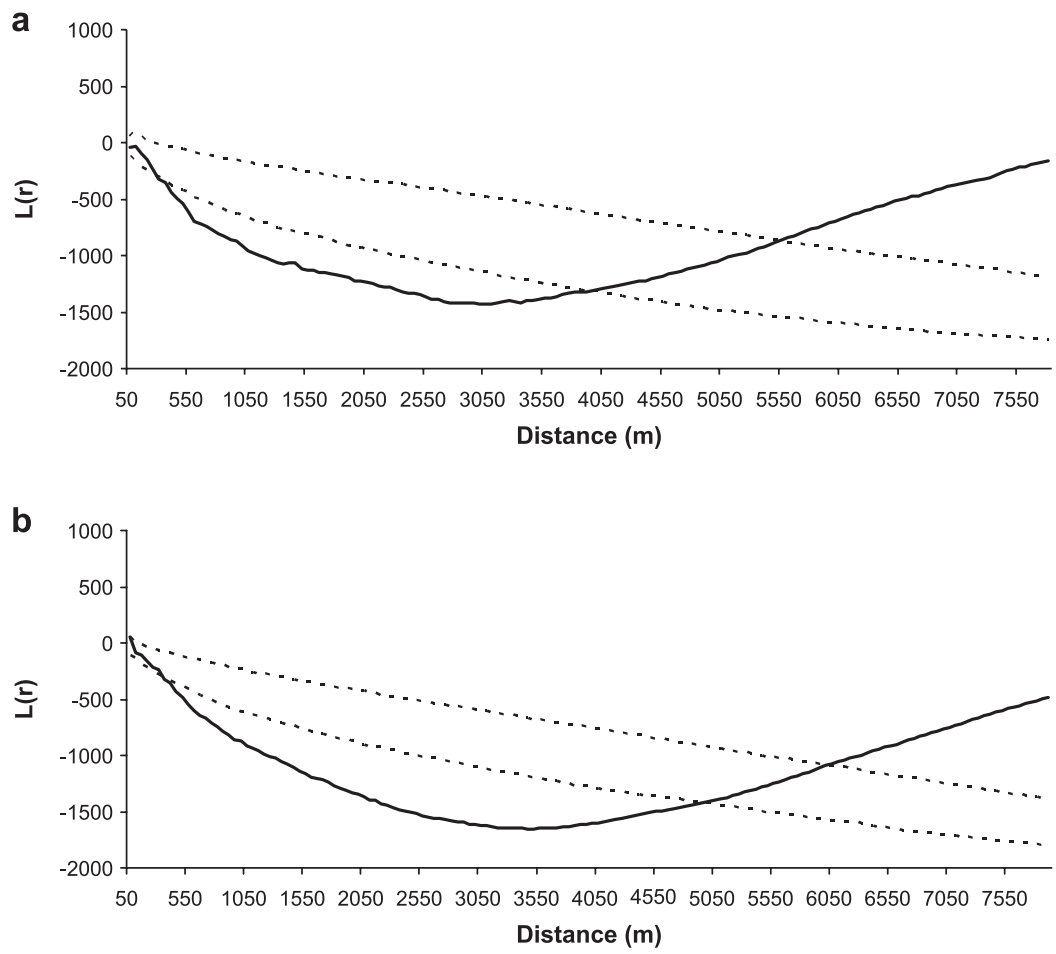

Figure 4. Results of the analyses of Ripley's bivariate function L(r) (solid line) of the distribution of Great Bustard nests in Castro Verde in relation to the centroids of cereal fields (a) and fallow fields (b), which are the habitat types preferred by Great Bustard females for nesting. All data correspond to year 2003. The dashed lines represent $95 \%$ confidence limits resulting from the randomisation of the distribution pattern (999 simulations). L(r) values within the $95 \%$ confidence limits indicate a random distribution, values below the interval indicate spatial aggregation and values above the interval indicate uniform distribution.

average of 2.47 eggs per clutch for a sample of 30 nests in north-west Spain, and Morgado and Moreira (2000) calculated an average clutch size of 2.6 (range 2-3 eggs per clutch) for a sample of 16 nests in the same area of the current study. However, the small sample sizes of these latter studies do not allow reliable comparisons or the identification of consistent temporal or geographical trends.

On the other hand, the lack of a relationship between clutch size and nest finding date in our study reveals no clear seasonal trend of reduction of later (or replacement) clutches as described for many bird species (Klomp 1970, Cooper et al. 2005), including the Great Bustard (Fodor 1974, Faragó 1992). However, the significant year-to-year delay in nest finding date reveals an interannual trend probably related to yearly climatic differences. In fact, there was an increase in autumn rainfall in the study area during the three study years (Rocha 2006), which resulted in a progressive year-to-year delay in the date of cereal sowing. This caused a delay in the development of vegetation so that the adequate vegetation structure for nesting was probably attained later each year. This could explain why females nesting in cereals (the majority of them, in fact) tended also to start nesting later each year. Additionally, an increase in the intensity of early spring rainfall was recorded in the area over the study period (Rocha 2006), which may explain the significant year-to-year delay of one-egg clutches: laying in general is delayed, but most particularly one egg clutches, which should mainly correspond to replacement ones (Faragó 
1992). Other studies have also shown a negative effect of stormy spring rainfall on Great Bustard productivity (Morales et al. 2002).

\section{Nesting success}

Existing reports on hatching success and nest survival in the Great Bustard are scarce. Ena et al. (1987) estimated that only 50\% of eggs laid in the Spanish population of Villafáfila finally hatched, and Flint and Mishchenko (1991) reported a 20-25\% hatching success of first clutches in the Saratov region. These low figures, although expected for a ground-nesting bird (Yanes and Suárez 1995), contrast with the relatively high nesting success ( $71 \%)$ found in the present study. This relatively high nesting success may be, at least in part, a result of the habitat management measures applied in the Castro Verde SPA during the last 15 years, under the scope of conservation projects and agri-environmental policies to promote farming management compatible with bird conservation (Pinto et al. 2005). These measures include actions aiming at maintaining suitable nesting and feeding habitats (through promoting traditional crop rotations and regulating new afforestation), reducing livestock densities, matching timing of cereal harvest and ploughing of fallows to the breeding phenology of the birds, avoiding mortality and disturbance in nesting grounds (promoting modification in hazardous power lines, regulating new fences and hunting disturbance) and raising public awareness. These measures have probably contributed to reduce female mortality, disturbance, nest destruction by agricultural works and nest trampling by livestock, and to increase feeding conditions, which have most likely increased nesting success.

In spite of the above mentioned conservation measures, agricultural works involving machinery (mainly ploughing, mowing and harvesting) were the main cause of nest loss in the area. This threat is also the most frequently identified in other study areas, from the Iberian Peninsula to Hungary and Russia (Sterbetz 1980, Ena et al. 1987, Flint and Mishchenko 1991) and is clearly linked to the increasing intensification of agriculture that occurred in Europe during the second half of the 2oth century (Sandersson et al. 2005). Nevertheless, the estimated percentage of losses due to agricultural activity found in this study $(14.9 \%)$ is clearly smaller than those reported for other areas $50 \%$ in north-western Spain and $70 \%$ for Hungary; Ena et al. 1987 and Sterbetz 1980, respectively), which, again, may be a positive consequence of the management measures applied in Castro Verde. In any case, nest losses due to agricultural works are a clear and widespread threat to populations of Great Bustard and other farmland birds (Beintema and Müskens 1987, Green et al. 1987, Onrubia and Andrés 2005) and there is a general consensus among experts on the need to halt or minimise such operations during the species's nesting period (Moreno et al. 2010). The other two causes of nest loss, predation and livestock trampling, are widely documented in the Great Bustard (BirdLife International 2000, Morales and Martín 2002, Langgemach and Bellebaum 2005, Watzke 2007) and other ground-nesting birds (Beintema and Müskens 1987, Yanes and Suárez 1995). Corvids in particular are considered important predators of Great Bustard eggs (Ena et al. 1987, Flint and Mishchenko 1991, Morales and Martín 2002). In relation to livestock trampling, there is a need to regulate and even eliminate grazing load during the nesting period (Moreno et al. 2010). In the case of Castro Verde this is particularly relevant, given the importance of extensive sheep and cattle grazing in the region and the large area of fallow land and pastures.

\section{Nesting habitat use and selection}

Great Bustard nests in Castro Verde were spatially aggregated, occupying a minimum area of 44.I ha, which can be considered a realistic approximation to the real area used for nesting by Great Bustard females in the study area, given the exhaustive and homogeneous sampling effort. Aggregated spatial distribution patterns have been suggested for other studied populations (Alonso et al. 2004, Magaña et al. 2010), although this is the first study in which such aggregation has actually been measured and tested. Although it is not always the case (see 
Magaña et al. 2011), aggregation of nests in the Great Bustard often occurs in the vicinity of male lekking arenas (Alonso et al. 2000, Magaña et al. 2010), which is a common pattern among lekking birds (see Höglund and Alatalo 1995). On the other hand, the range of distances at which nest clustering occurs can be used as a criterion to spatially delimit the application of management measures aimed at increasing nesting success. Nest density (locally, up to eight nests/Iooo ha), was similar to that found in other large populations of the species, such as Villafáfila, where Ena et al. (1987) reported 5.15 nests/100o ha.

Great Bustards in Castro Verde nest mainly in fallow fields and cereals, and very rarely in ploughed fields and young tree plantations. Although more nests were found in fallow land, cereal fields were the more intensely selected habitat type for nesting. The next most selected habitat types were young fallows, closely followed by old fallows. This nesting habitat selection pattern is similar to that found in other Great Bustard populations in Germany, Hungary and Spain (Petrick 1996, Faragó et al. 2001, Magaña et al. 2010), as well as to that described by Morgado and Moreira (2000) for a much smaller sample from Castro Verde. Both cereal fields and fallows probably provide the required anti-predator shelter for incubating females, in addition to adequate insect food supply (García and Arroyo 2005, Traba et al. 2008). Predation of nests and incubating parents is a widespread and strong selection pressure in ground nesting birds (Yanes and Suárez 1995), including Great Bustard (Martín 2008), whose habitat selection at the vegetation structure level can be considered a result of a trade-off between the need for concealment and the need for anti-predator survey (Morales and Traba 2009, Magaña et al. 2010). In this respect, Morales and Traba (2009) showed that the vegetation structure selected by breeding females largely coincides with that generally found in cereal fields.

Yearly differences in the selection of fallows (highest in 2002 and 2003) and cereal fields (highest in 2004) may be related to the state of cereal growth in the corresponding year. As mentioned above, cereal sowing in 2004 was delayed due to excessive autumn rainfall, which produced a sparser cereal structure more suitable for nesting (pers. obs.). So the stronger selection of cereal fields in 2004 suggests that the difference was caused by the greater attractiveness of this habitat type.

The high selection for fallows (which are, in fact, the most intensely selected habitat type in some studies; see Magaña et al. 2010) poses an interesting question related to the management of cereal pseudo-steppes. In very intensive cereal farmland, fallows can play a key role as refuge habitat when too densely sown cereal fields prevent utilisation by Great Bustards and other species. However, in less intensive areas, where fields are more sparsely covered by cereal plants due to climate conditions or poorer soils, cereals would be preferred by Great Bustards (such is the case of Castro Verde), whereas fallows (normally with shorter vegetation due to grazing) are more frequently selected by smaller-body sized species such as Little Bustard Tetrax tetrax or Calandra Lark Melanocorypha calandra, which tend to avoid cereals (Morales et al. 2008, Morgado et al. 2010, Silva et al. 2010). Land management recommendations for farmland bird conservation and agri-environment schemes (AES) should consider these site-specific differences, as well as the implications of changing agricultural policies (currently promoting the abandonment of cereal cultivation in Castro Verde) and climate change. Finally, the spatial association at intermediate scale between nest locations and areas where both cereals and fallows are present highlights Great Bustards' dependence on landscapes dominated by the cereal-fallow mosaic generated by the culture rotation systems typical of Mediterranean dry farming. Therefore, these extensive agricultural landscapes should be maintained (e.g. via cross-compliance extensification measures) in order to conserve this and other steppe bird species.

\section{Acknowledgements}

We are indebted to all the people who provided valuable field information, particularly the shepherds, farmers and field biologists of the Campo Branco region. P. Rocha was financed by Grant SFRH/BD/3141/200o from the Fundação para a Ciência e Tecnologia of Portugal. 


\section{References}

Alonso, J. C., Martin, C. A., Alonso, J. A., Palacin, C., Magaña, M. and Lane, S. J. (2004) Distribution dynamics of a great bustard metapopulation throughout a decade: influence of conspecific attraction and recruitment. Biodivers. Conserv. 13: 1659-1674.

Arthur, S. A., Manly, B. F., McDonald, L. L. and Garner, G. W. (1996) Assessing habitat selection when availability changes. Ecology 77: 215-227.

Báldi, A., Batáry, P. and Erdős, S. (2005) Effects of grazing intensity on bird assemblages and populations of Hungarian grasslands. Agric. Ecosyst. Environ. 108: 251-263.

Beintema, A. J. and Müskens, G. J. D. M. (1987) Nesting success of birds breeding in Dutch agricultural grasslands. J. Appl. Ecol. 24: $743-758$.

BirdLife International (2000) Threatened birds of the world. Barcelona, Spain and Cambridge, UK: Lynx Edicions and Birdlife International.

Cooper, C. B., Hochachka, W. M., Butcher, G. and Dhondt, A. A. (2005) Seasonal and latitudinal trends in clutch size: thermal constraints during laying and incubation. Ecology 86: 2018-2031.

Cramp, S. K. and Simmons, E. L. (1980) The birds of the Western Palearctic. Vol. 2. Oxford: Oxford University Press.

Del Hoyo, J., Elliot, A. and Sargatal, J. (1996) Handbook of the birds of the world. Vol. III. Hoatzins to auks. Barcelona: Lynx Edicions.

Ena, V. Martínez, A. and Thomas, D. H. (1987) Breeding success of the Great Bustard Otis tarda in Zamora Province, Spain, in 1984. Ibis 129: 364-370.

ESRI- Environmental Systems Research Institute (1999) ArcView GIS 3.2.

Faragó, S. (1992) Clutch size of the Great Bustard (Otis tarda) in Hungary. Aquila 99: 69-84.

Faragó, S., Giczi, F. and Wurm, H. (2001) Management for the great bustard (Otis tarda) in Western Hungary. Game Wildl. Sci. 18: 171-181.

Flint, V. E. and Mishchencko, A. L. (1991) The Great Bustard in the USSR. Pp. 89-90 in P. D. Goriup, L. A. Batten and J. A. Norton, eds. Status and conservation of lowland and dry grassland birds in Europe. Reading, UK: Joint Nature Conservation Committee.

Fodor, T. (1974) A túzok fészkelésbiologiája. A Vadgazdálkodás Fejlesztése 11: 19-23.

García, J. T. and Arroyo, B. E. (2005) Food-niche differentiation in sympatric Hen Circus cyaneus and Montagu's Harriers Circus pygargus. Ibis 147: 144-157.

Green, R. E., Hawell, J. and Johnson, T. H. (1987) Identification of predators of wader eggs from egg remains Bird Study 34: 87-91.

Grimmet, R. F. A. and Jones, T. A. (1989) Important Bird Areas in Europe. Cambridge, UK: International Council for Bird Preservation (ICBP Technical Publication No. 9).

Guerrero, I., Morales, M. B., Oñate, J. J., Aavik, T., Bengtsson, J., Berendse, F., Clement, L. W., Dennis, C., Eggers, S., Emmerson, M., Fischer, C., Flohre, A., Geiger, F., Hawro, V., Inchausti, P., Kalamees, A., Kinks, R., Liira, J., Meléndez, L., Pärt, T., Thies, C., Tscharntke, T., Olszewski, A. and Weisser, W. W. (2011) Taxonomic and functional diversity of farmland bird communities across Europe: effects of biogeography and agricultural intensification. Biodivers. Conserv. 20: 3663-3681.

Höglund, J. and Alatalo, R. V. (1995) Leks. Princeton, New Jersey: Princeton University Press. (Monographs in behavior and ecology).

Hooge, P. N. and Eichenlaub, W. (1997) Animal movement extension to Arcview. US Geological Survey.

Klomp, H. (1970) The determination of clutch size in birds. Ardea 58: 1-124.

Lane, S. J. and Alonso, J. C. (2001) Status and extinction probabilities of great bustard (Otis tarda) leks in Andalucía, southern Spain. Biodivers. Conserv. 10: 893-910

Langgemach, T. and Bellebaum, J. (2005) Predation and the conservation of groundbreeding birds in Germany. Vogelwelt 126 : 259-298.

Lopez-Jamar, J., Casas, F., Diaz, M., Morales, M. B. (2011) Local differences in habitat selection by Great Bustards Otis tarda in changing agricultural landscapes: 
implications for farmland bird conservation.

Bird Conserv. Internat. 21: 328-341.

Magaña, M. (2007) Comportamiento reproductivo de la Avutarda Común. PhD Thesis, Universidad Complutense de Madrid. Madrid: UCM.

Magaña, M., Alonso, J. C., Martín, C. A., Bautista, L. M. and Martín, B. (2010) Nestsite selection by Great Bustards Otis tarda suggests a trade-off between concealment and visibility. Ibis 152: 77-89.

Magaña, M., Alonso, J. C., Alonso, J. A., Martin, C. A., Martin, B., Palacin, C. (2011) Great Bustard (Otis tarda) nest locations in relation to leks. J. Ornithol. 152: $541-548$.

Manly, B. F., McDonald, L. L. and Thomas, D. L. (1993) Resource selection by animals: Statistical design and analysis for field studies. London: Chapman and Hall.

Martín, B. (2008) Dinámica de población y viabilidad de la Avutarda Común en la Comunidad de Madrid. PhD Thesis, Universidad Complutense de Madrid. Madrid: UCM.

McGowan, C. P., Millspaugh, J. J., Ryan, M. R., Kruse, C. D. and Pavelka, G. (2009) Estimating survival of precocial chicks during the prefledging period using a catchcurve analysis and count-based age-class data. J. Field Ornithol. 80: 79-87.

Morales, M. B. and Martín, C. A. (2002) The Great Bustard Otis tarda. BWP Update 4: 217-232.

Morales, M. B. and Traba, J. (2009) Compromisos adaptativos en la selección de hábitat de aves esteparias. Pp. 307-316 in H. Dopazo and A. Navarro, eds. Adaptación y evolución: 150 años después del Origen de las Especies. Valencia: Ediciones Obrapropia.

Morales, M. B., Alonso, J. C. and Alonso, J. A. (2002) Productivity and female individual breeding success in a great bustard Otis tarda population. Ibis 144: 285-283.

Morales, M. B., Traba, J., Carriles, E., Delgado, M. P. and García de la Morena, E. L. (2008) Sexual differences in microhabitat selection of breeding Little Bustards Tetrax tetrax: ecological segregation based on vegetation structure. Acta Oecol. 34: 345-353.

Moreira, F., Morgado, R. and Arthur, S. (2004) Great bustard Otis tarda habitat selection in relation to agricultural use in southern Portugal. Wildl. Biol. 10: 251-260.

Moreno, V., Morales, M. B. and Traba, J. (2010) Avoiding over-implementation of agri-environmental schemes for steppe bird conservation: a species-focused proposal based on specialist criteria. J. Environ. Manage, 91: 1802-1809.

Morgado, R. and Moreira, F. (2000) Seasonal population dynamics, nest site selection, sex-ratio, and clutch size of the great bustard Otis tarda in two adjacent lekking areas. Ardeola 47: 237-246.

Morgado, R., Beja, P., Reino, L., Gordinho, L., Delgado, A., Borralho, R. and Moreira, F. (2010) Calandra lark habitat selection: Strong fragmentation effects in a grassland specialist. Acta Oecol. 36: 63-73.

Onrubia, A. and Andrés, T. (2005) Impact of human activities on steppic-land birds: a review in the context of the Western Palearctic. Pp. 185-210 in G. Bota, M. B. Morales, S. Mañosa and J. Camprodon, eds. Ecology and conservation of steppe-land birds. Barcelona: Lynx Edicions.

Palacín, C. and Alonso, J. C. (2008) An updated estimate of the world status and population trends of the great bustard Otis tarda. Ardeola 55: 13-25.

Petrick, S. (1996) Zur Brutplatzwahl der Großtrappe (Otis tarda L., 1758) im Land Brandenburg. Naturschutz und Landschaftplege in Brandenburg 1: 99-102.

Pinto, M. and Rocha, P. (2006) The situation of great bustard Otis tarda in Portugal. Pp. 20-25 in D. Leitão, C. Jolivet, M. Rodriguez and J. Tavares, eds. Bustard conservation in Europe in the last 15 years: current trends, best practice and priorities. Cambridge, UK: BirdLife International.

Pinto, M., Rocha, P. and Moreira, F. (2005) Long-term trends in great bustard (Otis tarda) populations in Portugal suggest concentration in single high quality area. Biol. Conserv. 124: 415-423.

Ripley, B. D. (1981) Spatial statistics. New York: Wiley.

Rivas-Martínez, S. (1981) Les étages bioclimatiques de la végetation de la Péninsule Iberique. Anales Jard. Bot. Madrid 37: 251-268.

Rocha, P. (2006) Dinâmica populacional e distribução da abetarda no Baixo-Alentejo: 
Relação com o uso da terra. PhD Thesis. Universidade Técnica de Lisboa-Instituto Superior de Agronomia. Lisbon: UTL

Rosenberg, M. S. (2009) PASSaGE: Pattern analysis, spatial statistics and geographic exegesis. Version 2 ( $\beta$ 2.0.9.24). www. passagesoftware.net

Sandersson, F., Donald, P. F. and Burfield, I. J. (2005) Farmland birds in Europe: from policy change to population decline and back again. Pp. 211-236 in G. Bota, M. B. Morales, S. Mañosa and J. Camprodon, eds. Ecology and conservation of steppe-land birds. Barcelona: Lynx Edicions.

Shlyakhtin, G. V., Tabachishin, V. G. Khrustov, A. V. and Zav'yalov, E. V. (2004) Ecological segregation of bustards (Otididae) in the north of the Lower Volga region: evolutionary and adaptive aspects. Russ. J. Ecol. 35: 247-253.

Silva, J. P., Palmeirim, J. M. and Moreira, F. (2010) Higher breeding densities of the threatened little bustard Tetrax tetrax occur in larger grassland fields: Implications for conservation. Biol. Conserv. 143: 2553-2558.

Sterbetz, I. (1980) Present situation of Great Bustard Otis tarda in Hungary. Pp. 114-117 in P. D. Goriup and V. Harsh, eds. Bustards in decline. Jaipur: Tourism and Wildlife Society of India.

Streich, W. J., Pitra, C., Litzbarski, H. and Quaisser, C. (1996) Zur Populationsdynamik der Großtrappe (Otis tarda L., 1758): eine Computersimulation. Naturschutz und Landschaftplege in Brandenburg 1: 91-94.

Sutherland, W. J. (2000) The conservation handbook. Research, management and policy. London: Blackwell.

Sutherland, W. J., Newton, I. and Green, R. E. (2004) Bird conservation and ecology. $A$ handbook of techniques. Oxford: Oxford University Press.

Traba, J., Morales, M. B., García de la Morena, E., Delgado, M. P. and Kristin, A. (2008) Selection of breeding territory by little bustard (Tetrax tetrax) males in Central Spain: the role of arthropod availability. Ecol. Res. 23: 615-622.

Tucker, G. M. and Heath, M. F. (1994) Birds in Europe: their conservation status. Cambridge, UK: BirdLife International.

Watzke, H. (2007) Reproduction and causes of mortality in the breeding area of the Great Bustard in the Saratov region of Russia. Bustard Stud. 6: 53-64.

Wiegand, T. and Moloney, K. A. (2004) Rings, circles, and null-models for point pattern analysis in ecology. Oikos 104: 209-229.

Yanes, M. and Suárez, F. (1995) Nest predation patterns in ground-nesting passerines on the Iberian Peninsula. Ecography 18: $423-428$

Zar, J. H. (1996) Biostatistical analysis. London, UK: Prentice Hall.

\section{PEDRO ROCHA, FRANCISCO MOREIRA}

Centro de Ecologia Aplicada "Prof. Baeta Neves", Instituto Superior de Agronomia Universidade Técnica de Lisboa, Tapada de Ajuda, 1349-017 Lisboa, Portugal.

MANUEL B. MORALES*

Depto. de Ecología, Facultad de Ciencias, Universidad Autónoma de Madrid. C/ Darwin 2, 28049. Madrid, Spain.

*Author for correspondence; email: manuel.morales@uam.es

Received 4 November 2011; revision accepted 26 March 2012; Published online 16 July 2012 